stration and adult education keeping up with personnel needs of the junior college? Why aren't those majoring in adult education being hired as adult education administrators in the junior colleges? Is below-college administrative experience adequate experiential training for a person assuming the responsibilities of a junior college adult education administrator? Is teaching at any level adequate experiential background for the adult edu- cation administrator? What is the relationship between administrative background (job experience and education) and the quantity and quality of adult education programs administered? What is the relationship between administrator background and his attitude toward and cooperation with other adult education agencies in the community? Once again, these questions await answers from those equal to the challenge.

1Dr. Raymond E. Schultz is a Professor of Higher Education at the Florida State University and Co-Director of the Southeastern Regional Junior College Leadership Program.

${ }^{2}$ The results of this study appear in a pamphlet entitled, Administrators for America's Junior Colleges: A Prediction of Need 1965-1980. This pamphlet can be obtained for $\$ .50$ a copy from the American Association of Junior Colleges, 1777 Massachusetts Ave., N.W., Washington, D.C.

${ }^{8}$ The authors isolated the 127 adult education administrators from a much larger list of administrative staff members by the titles they were given. Although title variations were numerous, most of them were referred to as either deans, directors or coordinators of either adult, evening, or extension programs.

\title{
A Study of Community Leaders' Perceptions
}

\author{
Howard Y. McClusky \\ Community Adult Education Department \\ University of Micbigan
}

THe volunteer, especially the volunteer community leader, has long been regarded as a major catalyst of democratic behavior in the American community. It is claimed that the contagion of his example produces a climate favorable for the development of contributed services, and that his participation in making decisions about problems affecting the general welfare helps distribute the exercise of power throughout the community instead of allowing it to drift by default into the hands of a privileged elite.
Although the community leader has been the object of much acclaim, he 'as not as frequently been the subject of systematic inquiry as the importance of his role would indicate. What does the volunteer leader think of his community? Does he believe that it has any serious problems requiring attention? If so, what are they and what are the chances for their solution? This article is the report of a study designed to throw light on these and similar questions related to the leader's role as an agent of community improvement. 
In recent years the Department of Community Adult Education at the University of Michigan has held fortyone "Area Conferences" for community leaders in all sections of the state. The conferences have been attended usually by persons from communities within a radius of approximately thirty miles from the conference location and consist of an afternoon, dinner, and evening session devoted to problems common to the communities represented. Over 3,000 leaders from more than 200 communities have been involved. As part of a larger investigation to determine the impact of the conference on those taking part, it was necessary to secure data for establishing a base line of attitude with which to compare the response of the participants at the end of the conference. The data presented in this report constitute the base line phase of the larger investigation.

\section{Subjects and Method}

The subjects of the investigation were persons designated as community leaders by the superintendent of schools in the communities in which they lived. Data were secured by the administration of (approximately) an hour-long interview with a nonrandom population of 178 leaders in seventeen towns in southeastern Michigan. The towns ranged from 500 to 6,000 in size. Of the group, 116 were men and 62 women; 152 were between the ages of thirty and sixty; 112 had completed one or more years of college. Members of the professions composed the largest occupational group with 59; housewives were next with 47 , followed by managers, cleri- cal and sales personnel with 19 each, 15 business owners, 9 farmers, and a few skilled and semi-skilled workers.

The income for the sample ranged from average to above; the distribution for length of residence was bimodal, 47 relative "newcomers" having lived in their respective towns fewer than six years, 75 "oldtimers" having lived there nineteen or more years. Almost half the group (83) belonged to three or more organizations. In other words the subjects of this investigation had characteristics similar to those revealed by most studies of community participation. For the most part they were active in organizational life, and in income, occupation and education came from the middle and upper level of the general population.

\section{Attifudes}

When asked, "How do you feel about living in your town?", combining the two favorable categories in a Likert type scale, eighty-eight per cent approved of their communities, nine per cent were non-commital while only three per cent disapproved. In order to test the strength of this attitude they were also asked: "Other things being equal, would you move to another community if you had a chance?" In reply, sixty-nine per cent said no, twenty per cent said yes, while eleven per cent were undecided.

Although we lack control data, the preceding results indicate that a large majority of the subjects of our study have strong positive feelings for the communities in which they live.

Is the community leader likely to be complacent or sensitive about the im- 
perfections of his community? In answering this question we might hypothesize that because of their favorable social position and attachment to the community our leaders would be satisfied generally with things as they are and would regard a criticism of local affairs as incompatible with their community pride. On the other hand, one could argue that the leaders' satisfactions were incomplete and had really aroused aspirations for levels of community living which they had not yet attained. If this were true, one would expect them to be aware if not disturbed by imperfections in their respective localities and quite prepared to acknowledge them. There is considerable presumptive evidence in this study for the latter view, because our subjects were known to the school superintendents, who nominated them, to be active in community affairs and were presumably using their leadership as a way of contributing to community improvement.

In reviewing the results we find that the members of our sample were sharply aware of imperfections in their communities. In response to one question a large majority listed "unsolved problems"; in response to another, an equal number cited problems which they ranked as "most important"; in a third instance they freely reported disadvantages to living in their home towns. In addition, seventy-three per cent felt that the problems which they had cited as "unsolved" were especially crucial at the time of interview. The evidence, then, for leader awareness of problems is quite convincing.

But to what extent was this sensitivity shared by other members of the communities? In order to secure in- formation on this point the following question was used: "To what extent do you think that the people of your community are aware of the problem which you believe is "most important'?" In reviewing Table I we should remember that because the tabulation is based on leaders' perceptions, the data constitute an inferential and not a direct indication of community awareness.

According to Table I most of our community leaders believe that their awareness of community problems is shared by a majority of their fellow citizens.

\section{Table I}

Leaders' Perception of Community Awareness

$\begin{array}{cccc}\begin{array}{c}\text { Everyone } \\ \text { is Aware }\end{array} & \begin{array}{c}\text { Most People } \\ \text { are Aware }\end{array} & \begin{array}{c}\text { About Half } \\ \text { are Aware }\end{array} & \begin{array}{c}\text { Pew } \\ \text { or None } \\ \text { are Aware }\end{array} \\ 23 \% & 30 \% & 13 \% & 34 \%\end{array}$

About what kinds of problems were the leaders concerned? Data on this question were secured by the use of responses to three questions: first, "What are some of the most important problems in your town that have not been solved?" Second, "Which of the problems you mentioned is the most important to the community?" And third, "Most towns have some disadvantages, what do people say are the disadvantages in your town?" The results of these inquiries are presented in Table II.

According to Table II the problems cited by our respondents cluster around the areas of physical facilities, community planning, business and industry, youth and schools. A breakdown of replies by sex indicated that women are much more concerned with problems of youth and school than men. 
Unsolved

Most Important

Disadvantages
Table II

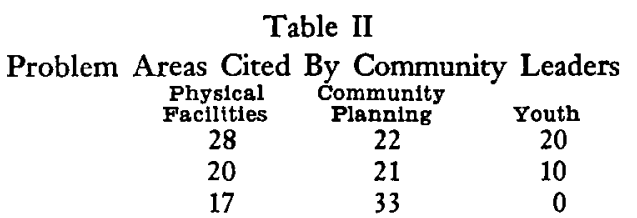

The above figures are percentages. They do not total $100 \%$ because items having smaller frequencies are not listed.

\section{Organizations' Influence}

In our society a person can volunteer his services in his own way or relate unilaterally to any other person or agency of his own choosing. This is one of the unique features of American citizenship and because of the creeping formalization or organizational life should be cherished and encouraged. In most cases, however, a volunteer can also contribute his talent through the organizations of which he is a member. He may be effective as a solo performer, but he is just as likely to be effective, if not more so, as a member or an officer of an organized group. Because of this fact, and because as indicated earlier, at least half of our sample belonged to three or more organizations, an attempt was made to discover what organizations our subjects perceived as having potential influence, and which ones were known as playing an active role in community problemsolving at the time of the investigation.

Accordingly our sample was asked: "Of all the organizations in the community, which are the ones most likely to be successful in getting things done for the community as a whole?"

In reply, service clubs were mentioned by 58 per cent, business groups by sixteen per cent, veteran's organizations and school groups by six per cent each with the remaining fourteen per cent distributed among church, fraternal, farm, and government affiliated groups. But when subjects were asked: "Are there any organizations currently working on this problem?" 60 per cent said yes, 31 per cent said no, and nine per cent did not know. Then when asked: "What organizations are they?" service clubs were mentioned most frequently, this time however, by 24 per cent (not by 58 per cent as before), church groups by 15 per cent, business groups by 8 per cent, fraternal groups by 4 per cent, veteran's groups by one, with no reference to farm, governmental and school groups and 47 per cent saying they didn't know of any.

The discrepancies disclosed by the responses to the preceding questions should after all not be too surprising. What an organization actually does should not necessarily tally with what its friends think it can do. There will necessarily be some gap between the ascribed potential and the operationally actual. And we do not know how large this gap should be when little data of this type are available for purposes of comparison.

\section{Conspicuous Facts}

But some facts are conspicuous and worth special comment. In response to both questions, service clubs stood first. Churches were scarcely mentioned as an agent of potential influence 
but were second (15) when performance was the basis of selection. Particularly noteworthy was the fact that 47 per cent reported being unaware of any organizations working on the important problems to which they had referred. Because these respondents were probably themselves members of organizations, this degree of ignorance suggests either that the organizations to which they belong were not engaged in community service or that their own participation was so meager that they were out of touch with what their groups or organizations were doing.

There may be some comfort in the fact that 36 per cent of the sample said they knew of organizations which had worked actively on important problems in the past, while 60 per cent reported knowing of organizations that were working on such problems at the time of the investigation. This difference between 36 and 60 per cent may mean simply that the memories of some fade away, or that the experience of others, e.g. the "newcomers" does not go back far enough, or that there has been an actual increase over the years of organizational activity on behalf of the community. In any case, it gives no evidence of an "old oaken bucket" attitude which might have ascribed great powers of problem solving to their favorite organizations in the "good old days."

\section{Individual Involvement}

After the members of the sample had been invited to state what they regarded to be the most important problem facing their community, they were then asked: "Are you now work- ing on the problems?" In reply 28 per cent said yes, and 72 per cent, no. When asked further: "Have you worked on the problem in the past?" the answer was 29 per cent yes, and 71 per cent no.

Because we have no control data with which to compare our results, we can not be sure of the meaning of the preceding distribution of responses. We would probably find fewer than 28 per cent of the rank and file working on problems which they regarded as most important for their community's well being, and it may be unrealistic to expect more than this number of leaders to be active at any given period because of the competing demands on their time and effort. On the other hand it might be argued that this is a low level of activity for the kind of person nominated as examples of leadership highly visible in community work.

In order to probe further about the character of their involvement, the subjects were asked: "Do you have, or have you had in the past any new ideas about how the community might solve the problem which you have named as most important?" In answer 43 per cent said yes, and 57 per cent, no; and in response to further inquiry only 18 per cent of the 43 per cent indicated that they had tried to put their ideas into effect.

\section{Willingness to Cooperate}

Initiation of a community project may be the outcome of either individual or group effort, but a project will not get very far beyond the point of take-off, unless early in the game the initiators establish favorable 
relationships with those who have the most to contribute to its development, as well as those most likely to be affected by its implementation. It will be recalled that the members of our sample had already established good records as performing community leaders. Because of this fact, an attempt was made to determine whether or not they saw themselves as "lone workers" or as potential members of a working team. At the same time we were interested in discovering any indirect evidence of factionalism in the communities in which they worked. In pursuing this line of inquiry, our subjects were asked first to list persons (other than themselves) whom they regarded as community leaders. After having done so, they were then asked: "Do you feel that you could fit in and work with them?" In response, 93 per cent said yes, three per cent were uncertain, while only four per cent said they could not. One finds here then a high degree of willingness on the part of our subjects to cooperate with other community leaders and little if any evidence of factionalism.

\section{Role Identification}

When members of our group were asked: "How and in what way" could they fit in and work with those they had named as leaders, 52 per cent responded with definite suggestions, while the remaining were uncertain about what they could do.

The replies of the unclear 48 per cent suggest two points especially relevant for the meaning of the investigation. First, possibly many of our aders may have lacked confidence in the relevance and level of their per- forming skills. Second, the role structure for community activities may have been so diffuse that our respondents were unable to state definitely what they could do.

\section{Table III}

Leaders' Estimate of Chance for Solution of Problems

$\begin{array}{cccc}\text { A Cood } & \text { A Fralr } & \begin{array}{c}\text { Very Poor } \\ \text { Chance }\end{array} & \begin{array}{c}\text { No } \\ \text { Chance }\end{array} \\ 29 \% & 39 \% & 22 \% & 5 \%\end{array}$

\section{Problem Solvability}

The concluding question of the interview schedule was aimed at discovering the general attitude of our subjects toward the solvability of the problems which they had designed as "important." More specifically they were asked: "What chance is there that problems you have mentioned can be solved?" Table III contains a summary tabulation of the answers to this question.

A pessimistically inclined reading of Table III could point out that 61 per cent of our sample believe that there is only a fair chance or less that the problem they have named as important could be solved. On the other hand a more optimistic view could point out that 68 per cent think there was a fair chance or better for the solution of the problem and could add that the most optimistic, i.e. those believing there is a "good chance" outnumber the most pessimistic, i.e. those believing there is no chance, by about 6 to 1 (i.e. $29 \%$ vs. $5 \%$ ).

The fact that a fair case can be made for either a moderately pessimistic or moderately optimistic interpretation of the above table can itself be interpreted as constituting a kind of "face validity" for our data. In other words in the light of the replies 
to the other questions of the investigation, the estimate of chances presented in Table III probably provides a reasonable base line of leader expectation toward the outcome of problem solving efforts.

\section{Inferprefation of Results}

It would be easy to dismiss the results of this study as little more than a montage of complaint, hope, and futility. But in the judgment of the writer this would reflect a superficial understanding of the realities one encounters in attempting to apply rational processes to the solution of community problems. It would constitute a skeptical over-reaction of a naive view which expects too much and too soon from intermittent and scattered efforts at community development.

It has taken our society many long centuries to develop minimal and standard ways of eating, writing, clothing, exchange and the many other processes involved in everyday living. But there are other areas of living for which standard answers are not and probably never will be available. To cite the problem areas disclosed by our study there are no ready-made and inherital formulae for keeping schools up-to-date, helping youth get a foothold in a changing economy, overcoming inadequate physical facilities, upgrading business and industry and in community planning.

\section{Adult Education Task}

It is the thesis of this discussion that the task of helping local leaders dis- cover viable solutions for problems created by continuing community change is one of the principal tasks of adult education. It is also our view that some idea of the dimensions of this task is contained in the discrepancy between the kinds of problems and the levels of performance revealed by our results.

At the same time our data afford a basis for believing that the communities represented in our study possess important resources for an educative approach to community development. In the first place it can be plausibly inferred that a large majority of our subjects have a genuine interest in improving their communities. Moreover, this interest is expressed by persons who by performance have demonstrated a capacity to get things done. In the second place their concern is more than a vague dissatisfaction but centers on specific areas of community living. In the third place, they believe that they are not alone in their interest but that it is shared by other persons holding positions of influence in the community and with whom they are willing to cooperate. And finally our data revealed a significant sub-group believing that something can be done about the problems which they have listed.

In conclusion we can plausibly infer that the communities represented in this study possess a substantial group of persons who are ready for and would be responsive to an educative effort designed to bring the needs and the performance of the community into a more productive relationship. 